\title{
Sequence divergence of Mus spretus and Mus musculus across a skin cancer susceptibility locus
} Kimberly L Mahler ${ }^{1}$, Jessica L Fleming ${ }^{2}$, Amy M Dworkin ${ }^{3}$, Nicholas Gladman ${ }^{1}$, Hee-Yeon $\mathrm{Cho}^{2}$, Jian-Hua Mao ${ }^{4}$, Allan Balmain ${ }^{4}$ and Amanda Ewart Toland*1,5

\begin{abstract}
Address: ${ }^{1}$ Division of Human Cancer Genetics, Department of Molecular Virology, Immunology and Medical Genetics, OSU Comprehensive Cancer Center, The Ohio State University, OH, USA, ${ }^{2}$ Molecular, Cellular and Developmental Biology Graduate Program, The Ohio State University, OH, USA, ${ }^{3}$ Integrated Biomedical Science Graduate Program, The Ohio State University, OH, USA, ${ }^{4} \mathrm{Cancer}$ Research Institute, University of California, San Francisco, San Francisco, CA, USA and ${ }^{5}$ Division of Human Genetics, Department of Internal Medicine, The Ohio State University, Columbus, OH, USA

Email: Kimberly L Mahler - kimberly.mahler@osumc.edu; Jessica L Fleming - jessica.fleming@osumc.edu; Amy M Dworkin - amy.dworkin@osumc.edu; Nicholas Gladman - gladman@wisc.edu; Hee-Yeon Cho - cho.277@osu.edu; JianHua Mao - JHMao@lbl.gov; Allan Balmain - abalmain@cc.ucsf.edu; Amanda Ewart Toland* - amanda.toland@osumc.edu

* Corresponding author
\end{abstract}

Published: 23 December 2008

BMC Genomics 2008, 9:626 doi:10.1 186/1471-2164-9-626

This article is available from: http://www.biomedcentral.com/147/-2/64/9/626

(c) 2008 Mahler et al; licensee BioMed Central Ltd.

This is an Open Access article distributed under the terms of the Creative Commons Attribution License (http://creativecommons.org/licenses/by/2.0), which permits unrestricted use, distribution, and reproduction in any medium, provided the original work is properly cited.
Received: 7 July 2008

Accepted: 23 December 2008

\begin{abstract}
Background: Mus spretus diverged from Mus musculus over one million years ago. These mice are genetically and phenotypically divergent. Despite the value of utilizing $M$. musculus and $M$. spretus for quantitative trait locus (QTL) mapping, relatively little genomic information on M. spretus exists, and most of the available sequence and polymorphic data is for one strain of M. spretus, Spret/Ei. In previous work, we mapped fifteen loci for skin cancer susceptibility using four different $M$. spretus by $M$. musculus $\mathrm{FI}$ backcrosses. One locus, skin tumor susceptibility 5 (Skts5) on chromosome 12, shows strong linkage in one cross.
\end{abstract}

Results: To identify potential candidate genes for $S k t s 5$, we sequenced 65 named and unnamed genes and coding elements mapping to the peak linkage area in outbred spretus, Spret/EjJ, FVB/NJ, and $\mathrm{NIH} / \mathrm{Ola}$. We identified polymorphisms in 62 of 65 genes including 122 amino acid substitutions. To look for polymorphisms consistent with the linkage data, we sequenced exons with amino acid polymorphisms in two additional $M$. spretus strains and one additional $M$. musculus strain generating $40.1 \mathrm{~kb}$ of sequence data. Eight candidate variants were identified that fit with the linkage data. To determine the degree of variation across $M$. spretus, we conducted phylogenetic analyses. The relatedness of the $M$. spretus strains at this locus is consistent with the proximity of region of ascertainment of the ancestral mice.

Conclusion: Our analyses suggest that, if $S k t s 5$ on chromosome 12 is representative of other regions in the genome, then published genomic data for Spret/Eij are likely to be of high utility for genomic studies in other $M$. spretus strains. 


\section{Background}

Mus spretus mice are derived from wild mice collected in Southern France, Spain and Northern Africa [1,2]. M. spretus diverged from Mus musculus one to three million years ago[3,4]. Recent data suggest that these mice are reported to have an average of one sequence variant every $50 \mathrm{bp}$ [5]. Strains of M. spretus are frequently utilized in combination with $M$. musculus strains in quantitative trait loci (QTL) studies due to the high degree of sequence and phenotypic diversity between the strains[6,7]. Indeed, M. spretus mice have been valuable for the identification of loci contributing to differences in immune response and inflammation [8-10]. M. spretus strains are also cancer resistant in comparison to several $M$. musculus strains and have been utilized for mapping of cancer susceptibility loci [11-16].

Unlike some of the other commonly used strains of mice for QTL mapping, none of the M. spretus strains have been fully sequenced. Few reports of comparisons of sequence diversity within $M$. spretus strains exist, and most have been generally limited to one gene or small genomic region [17-19]. The majority of the sequence, microsatellite, and single nucleotide polymorphism (SNP) data available for $M$. spretus mice are from Spret/Ei; for researchers using non-Spret/Ei strains of $M$. spretus, such as SEG/PAS mice, there is limited strain-specific information available in public databases.

In previous studies, we observed a large difference between $M$. musculus and $M$. spretus strains in susceptibility to chemically-induced skin cancer. M. spretus mice chemically treated with 7, 12-dimethylbenz [a] anthracene (DMBA) and 12-O-tetradecanoylphorbol-13-acetate (TPA) develop no skin papillomas after 20 weeks of treatment but M. musculus strains, such as NIH/Ola and FVB/ $\mathrm{N}$, develop an average of 20 or more papillomas [11]., To identify loci for skin cancer susceptibility we created four F1 backcrosses between M. spretus (Spret/EiJ, STF/PAS, outbred spretus) and M. musculus (FVB/NT, NIH/Ola) mice. Fifteen regions of linkage were identified [11$13,20,21]$. One locus, skin tumor susceptibility 5 (Skts5), a region on chromosome 12 with peak linkage at $17 \mathrm{cM}$ showed strong evidence of linkage in one F1 backcross $\mathrm{NIH} / \mathrm{Ola} \times \mathrm{F} 1(\mathrm{NIH} / \mathrm{Ola} \times$ outbred spretus $)$.

As one means of identifying potential skin cancer susceptibility candidate genes at Skts5, we sequenced all predicted genes in four of the strains used for linkage NIH/ Ola, FVB/NJ, outbred spretus, and Spret/EiJ. Exons that contained amino acid alterations between the strains were sequenced in two additional strains of M. Spretus (SEG/ PAS and STF/PAS) as well as FVB/NT (FVB/N mice, Taconics). Here, we describe the results from over $140 \mathrm{~kb}$ of sequence data from Skts5, $40.1 \mathrm{~kb}$ of which was sequenced in seven strains, and a phylogenetic comparison of the relatedness of four $M$. spretus strains.

\section{Results}

Confirmation of Skts5 as a skin tumor susceptibility locus Skin tumor susceptibility 5 (Skts5) was originally mapped as a skin tumor susceptibility locus to mouse chromosome 12 in a genome wide linkage analysis for skin cancer in an F1 backcross between NIH/Ola and outbred spretus mice $[11,12]$. We performed additional crosses between skin tumor resistant mice (Spret/EiJ, STF/PAS) and skin tumor susceptible mice (NIH/Ola, FVB/NT) to further test this locus for linkage $[13,20,21]$. We observed no evidence for linkage at Skts5 in the interspecific backcross NIH/Ola $\times$ [STF/PAS $\times$ NIH/Ola] or in the Spret/EiJ by FVB/NT F1 interspecific backcross. The linkage analysis for the Spret/ EiJ by NIH/Ola F1 interspecific backcross (approximately 80 mice) was inconclusive for linkage at Skts5. To refine the linkage region in the NIH/Ola $\times$ outbred spretus backcross, we genotyped additional markers on chromosome 12. Linkage analyses showed a peak LOD score of 3.2 at approximately $17 \mathrm{cM}$ (35 Mb; Figure 1).

Outbred spretus mice are not bred to homogeneity and segregate different polymorphisms and haplotypes across the genome. However, there was no evidence from the original linkage data generated from nine different outbred spretus fathers using 18 polymorphic markers for heterogeneity at Skts5. To further rule out the possibility of heterogeneity within these mice at Skts5, we genotyped seven additional microsatellite markers mapping to the peak linkage region of Skts5 in DNA from six non-littermate outbred spretus male mice. We observed no evidence of genetic heterogeneity (data not shown). From these results we felt reasonably confident that there was no genetic heterogeneity within our outbred spretus mouse colony at this locus.

\section{Identification of variants between $M$. musculus and $M$. spretus}

In order to identify polymorphic coding variants that fit the linkage data for Skts5, we first identified all known coding and non-coding genes at the peak region for linkage on chromosome 12 (between 31.7 and $47.9 \mathrm{Mb}$, Ensembl build 50) using genetic maps from the UCSC Genome Browser, Ensembl and Entrez Gene databases. Maps were updated and throughout our project to include newly mapped genes. At the conclusion of this study, 65 coding elements including ten hypothetical genes/coding elements, nine snoRNAs and one microRNA were identified as mapping within Skts5 (see Additional file 1). We designed PCR primers flanking all exons for the genes or coding elements mapping to Skts5. When multiple splice forms of a gene were predicted, we sequenced exons representing all splice variants. 


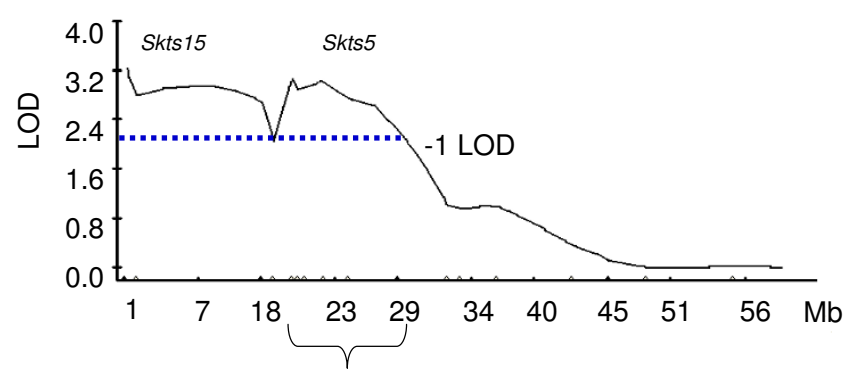

Skts5 peak

linkage region

\section{Figure I}

Linkage data at Skts5. Eighteen markers mapping to chromosome 12 were genotyped in $35 \mathrm{I} \mathrm{NIH/Ola} \times(\mathrm{NIH} / \mathrm{Ola} \times$ spretus outbred) backcross mice. Analysis using WinQTLcart shows two peak linkages. Skts 15 maps to proximal chromosome 12 and Skts 5 maps to chromosome 12 with a peak linkage at $\mathrm{ABI}$ marker E_29.924 (35 Mb, $17 \mathrm{cM}$ ). The one negative lod confidence interval is marked by a dotted line.

To carry out a screen for coding differences between the resistant strain of mice (outbred spretus) and the susceptible strain (NIH/Ola) that could be candidate variants for Skts5, we initially sequenced DNA from NIH/Ola, FVB/NJ, Spret/EiJ, and one outbred spretus animal. Exons containing amino acid variants were then sequenced in $\mathrm{FVB} / \mathrm{NT}$, SEG/PAS and STF/PAS. Variants shared between outbred spretus and STF/PAS were eliminated as candidates since STF/PAS does not show evidence for linkage at $S k t s 5$ in the $\mathrm{NIH} /$ Ola backcross. PCR product was obtained from both M. spretus and M. musculus DNA for all exons which rules out the possibility of large deletions in one strain of mice at this locus. Our analysis did not rule out the possibility of causal variants in regulatory regions or duplication or inversion copy number polymorphisms at this locus.

Analysis of sequence alignments of forward and reverse reads of 140,448 bp from genes and coding elements mapping to Skts5 led to the identification of 1,123 polymorphisms between M. musculus and M. spretus strains (Tables 1, 2 and Additional file 2). Of these, 122 resulted in amino acid substitutions, 121 occurred between $M$. musculus and M. spretus strains and one occurred between $\mathrm{NIH} / \mathrm{Ola}$ and $\mathrm{FVB} / \mathrm{NJ}$. There were six sequence differences identified between $\mathrm{FVB} / \mathrm{NJ}$ and NIH/Ola, but no differences between FVB/NT and NIH/Ola.

\section{Characterization of nucleotide substitutions at Skts5}

To further characterize the nucleotide variants, we analyzed polymorphisms on a gene by gene basis. The number of polymorphisms identified per gene ranged from no changes to 65 . The rate of substitution per nucleotide ranged from $3 / 3593(0.08 \%)$ in Nova1 to $8 / 133$ $(6 \%)$ in SNORNA17 (Ensembl ENSMUSG00000077294).
Because synonomous changes are less likely to affect protein function, these were not evaluated further in the other strains of mice used in the linkage crosses [22-24]. A catalogue of the types and locations of polymorphisms (Table 3: see Additional file 2) at Skts5 include the following changes: nonsense (1), missense (122), small insertion/ deletions (14), 5'UTR (89), 3'UTR (404) and potential splice-site alterations (23). To determine if the type of substitutions identified at Skts5 could shed light on the evolutionary forces between M. spretus and M. musculus, we looked at the number and percentages of nucleotide changes and the type of mutations (transitions versus transversions) in this data set (see Additional file 2). The transition to transversion ratio was approximately 2.0 (Figure 2). Given that $\mathrm{C}$ to $\mathrm{T}$ ( $\mathrm{G}$ to $\mathrm{A}$ ) transitions are a common mutation type due to the $\mathrm{CpG}$ methylation deamination process; these data are consistent with other large sequence comparisons $[25,26]$.

\section{Identification of variants within M. spretus}

We rationalized that in order for a bi-allelic polymorphism to be considered a candidate for Skts 5 that the cancer resistant strain (outbred spretus) would have one allele and the susceptible strain (NIH/Ola) would have the other. In addition, closely related strain STF/PAS that does not show evidence for linkage at Skts5 should not share alleles with outbred spretus. Of the 121 amino acid substitutions identified between $M$. musculus and M. spretus, three variants were present in Spret/EiJ but not the other M. spretus strains (Table 1 ). To rule out a sequencing or PCR artifact for those variants, new PCR product was generated and sequenced. All variants were confirmed as being unique to Spret/EiJ. Of the other 118 amino acid variants which were polymorphic between NIH/Ola and M. spretus, 99 were shared in all M. spretus strains analyzed and 19 were polymorphic between different M. spretus strains (Table 1). Eight variants fit our criteria for candidacy based on the linkage data (Table 4).

\section{Conservation of amino acid alterations}

Just as non-synonomous changes have a greater likelihood of affecting protein function than synonomous changes, non-synonomous changes that occur in a evolutionarily conserved residue are more likely to be functionally significant $[27,28]$. To assess amino acid polymorphisms for potential functional significance, proteins were compared using Ensembl ortholog prediction alignments between M. musculus and Homo sapiens, Pan troglyodytes, Gallus gallus, Rattus norvegicus, Canis familiaris, Bos Taurus, Xenopus tropicalis, Takifugu rubripes, and Monodelphis domestica when protein homologies existed http:// www.ensembl.org. If only one amino acid in the orthologous protein position was present in at least eight of the nine non-musuclus species examined, we considered that position to be strongly conserved. Twenty-four amino 
Table I: Amino acid variants within $M$. spretus strains

\begin{tabular}{|c|c|c|c|c|c|c|}
\hline Gene & Variant & EiJ & Outbred & SEG & STF & $\mathrm{NIH} / \mathrm{FVB}$ \\
\hline LambI-I & Gly1334Asn & Asn & Asn & Gly & Asn & Gly \\
\hline \multirow[t]{2}{*}{$\operatorname{Cog} 5$} & Asp538Glu & Glu & Glu & Asp & Glu & Asp \\
\hline & Asp742Glu & Glu & Glu & Glu & Asp & Asp \\
\hline I I I0049B09rik & Pro69IAla & Ala & Pro & Pro & Ala & Pro \\
\hline \multirow[t]{2}{*}{ F730043M I 9Rik } & SerlI5Leu & Leu & Leu & Ser & Leu & Ser \\
\hline & Asn I33lle & lle & Asn & Asn & Asn & Asn \\
\hline Twistnb & Asn322Asp & Asp & Asn & Asp & Asn & Asn \\
\hline \multirow[t]{3}{*}{ Hdac9 } & Ile265Met & Met & Met & Ile & Ile & Ile \\
\hline & Gly749Ser & Ser & Gly & Gly & Gly & Gly \\
\hline & Ala994Val & Val & Ala & Val & Ala & Ala \\
\hline \multirow[t]{2}{*}{ Ahr } & Asn533Ser & Ser & Ser & Asn & Asn & Asn \\
\hline & Asn544Asp & Asp & Asp & Asn & Asn & Asn \\
\hline \multirow[t]{3}{*}{ EG629820 } & Gly47Ser & Ser & Gly & Gly & Ser & Gly \\
\hline & Gly70Ser & Ser & Gly & Gly & Ser & Gly \\
\hline & Asn72Tyr & Asn & Tyr & Tyr & Asn & Asn \\
\hline \multirow[t]{2}{*}{$Z f p 277$} & Gln2IPhe & Phe & Phe & Val & Val & Gln \\
\hline & Val434His & His & His & Gln & His & Val \\
\hline \multirow[t]{3}{*}{ Lrrn3 } & Ala69Gln & Gln & Gln & Gln & Ala & Ala \\
\hline & Leu670Val & Val & Val & Val & Leu & Leu \\
\hline & Ala67IVal & Val & Ala & Ala & Ala & Ala \\
\hline DnajB9 & PhelOLeu & Leu & Phe & Phe & Phe & Phe \\
\hline $\mathrm{NrCam}$ & Gln I52Arg & Arg & Gln & Gln & Arg & Gln \\
\hline
\end{tabular}

acids showed strong conservation by this criterion (see Additional file 3).

In addition to sequence alignments, we assessed amino acid polymorphisms for potential functionality through a sequence homology-based tool Sorting Intolerant From Tolerant (SIFT)[28]. Using SIFT, the majority of amino acid polymorphisms were scored as tolerant substitutions. Surprisingly, a few amino acids that appear to be highly conserved across species, such as Pik3cg Ala405Thr, were scored as well-tolerated substitutions using SIFT. Eight variants were identified that were scored as intolerant substitutions by SIFT (scores 0.05 or less). These variants include Ahr Phe348Leu, Ankmy2 Ile369Thr, Sostdc1 Cys15Ser, Ifrd1 Leu449Phe, EG629820 Gly47Ser, Gly70Ser and Asn72Tyr and F730043M19Rik Asn133Ile. Of these, we identified three (Ahr Phe348Leu, Sostdc1 Cys15Ser and Ifrd1 Leu449Phe) in our initial ortholog 
Table 2: Potentially functionally significant amino acid variants

\begin{tabular}{|c|c|c|c|c|c|c|c|c|c|c|c|c|}
\hline Gene & Amino Acid & $M M$ & MS & $\mathrm{HS}$ & $\mathrm{RN}$ & GG & BT & $\mathrm{CF}$ & $\mathrm{XT}$ & $M D$ & $T R$ & SIFT \\
\hline Slc26a3 & His38Asn & $\mathrm{His}$ & Asn & $\mathrm{His}$ & His & $\mathrm{His}$ & $\mathrm{His}$ & $\mathrm{His}$ & His & $\mathrm{His}$ & His & 0.13 \\
\hline Dus4L & Cys I04Tyr & Cys & Tyr & Cys & Cys & Asn & Cys & Cys & Ser & Cys & Ala & 0.18 \\
\hline $\operatorname{Cog} 5$ & Ser769Ala & Ser & Ala & Ser & Ser & Ser & Ser & Ser & $\mathrm{NH}$ & Ser & Ser & 0.09 \\
\hline I I I0049B09Rik & Pro69IAla & Pro & Pro/Ala & Pro & Lys & Pro & Pro & Pro & Pro & Pro & $\mathrm{NH}$ & 0.11 \\
\hline F730043MI9Rik & Asn I33lle & Asn & lle/Asn & $\mathrm{NH}$ & $\mathrm{NH}$ & $\mathrm{NH}$ & $\mathrm{NH}$ & $\mathrm{NH}$ & $\mathrm{NH}$ & $\mathrm{NH}$ & $\mathrm{NH}$ & 0.00 \\
\hline 4930504H06Rik & Met64Val & Met & Val & Met & Met & $\mathrm{NH}$ & Met & Met & $\mathrm{NH}$ & Met & Phe & 0.13 \\
\hline \multirow[t]{2}{*}{ Ahr } & Leu348Phe & Leu & Phe & Leu & Leu & Leu & Leu & Leu & Leu & Leu & Leu & 0.01 \\
\hline & Ser790Gly & Ser & Gly & Asn & Ser & Asp & Asn & Asn & Asn & $\mathrm{His}$ & $\mathrm{NH}$ & 0.15 \\
\hline Ankmy2 & Ile369Thr & Ile & Thr & lle & Thr & Leu & Leu & Leu & Glu & Leu & $\mathrm{NH}$ & 0.03 \\
\hline Sostdcl & CysI5Ser & Cys & Ser & Cys & Cys & Cys & Cys & Cys & Cys & Cys & Cys & 0.00 \\
\hline IfrdI & Leu449Phe & Leu & Phe & Phe & $\mathrm{NH}$ & Phe & Phe & Phe & Leu & Phe & Phe & 0.00 \\
\hline \multirow[t]{3}{*}{ EG629820 } & Gly47Ser & Ser & Ser/Gly & $\mathrm{NH}$ & $\mathrm{NH}$ & $\mathrm{NH}$ & $\mathrm{NH}$ & $\mathrm{NH}$ & $\mathrm{NH}$ & $\mathrm{NH}$ & $\mathrm{NH}$ & 0.00 \\
\hline & Gly70Ser & Gly & Ser/Gly & $\mathrm{NH}$ & $\mathrm{NH}$ & $\mathrm{NH}$ & $\mathrm{NH}$ & $\mathrm{NH}$ & $\mathrm{NH}$ & $\mathrm{NH}$ & $\mathrm{NH}$ & 0.00 \\
\hline & Asn72Tyr & Asn & Tyr/Asn & $\mathrm{NH}$ & $\mathrm{NH}$ & $\mathrm{NH}$ & $\mathrm{NH}$ & $\mathrm{NH}$ & $\mathrm{NH}$ & $\mathrm{NH}$ & $\mathrm{NH}$ & 0.00 \\
\hline \multirow[t]{2}{*}{$Z f p 277$} & Val2IPhe & Val & Val/Phe & Ser & $\mathrm{NH}$ & $\mathrm{NH}$ & Asp & Asp & $\mathrm{NH}$ & $\mathrm{NH}$ & $\mathrm{NH}$ & 0.08 \\
\hline & $\mathrm{Gln} 43 \mathrm{His}$ & Gln & $\mathrm{G} \ln / \mathrm{His}$ & Gln & $\mathrm{NH}$ & Gln & Gln & Gln & Gln & Gln & Gln & 0.15 \\
\hline $\operatorname{Immp2L}$ & Ala8Val & Ala & Val & Val & Val & Gly & Val & Val & $\mathrm{NH}$ & Gly & Gly & 0.15 \\
\hline \multirow[t]{2}{*}{ Lrrn3 } & Ala69Gln & Ala & $\mathrm{Ala} / \mathrm{Gln}$ & Ala & Ala & Ala & Ala & Ala & $\mathrm{NH}$ & Ala & Leu & 0.08 \\
\hline & Ala67IVal & Ala & $\mathrm{Ala} / \mathrm{Val}$ & Ala & Ala & Ser & Ala & Thr & $\mathrm{NH}$ & Ala & $\mathrm{NH}$ & 0.15 \\
\hline Stxbp6 & Ile23Val & Ile & Val & Val & Val & Val & $\mathrm{NH}$ & Val & Val & Val & Val & 0.12 \\
\hline
\end{tabular}

Bold indicates significant SIFT scores. No known homology (NH), Mus musculus (MM), Mus spretus (MS), Homo sapiens (HS), Rattus norvegicus (RN), Gallus gallus (GG), Bos Taurus (BT), Canis familiaris (CF), Xenopus tropicalis (XP), Monodelphis domestica (MD), and Takifugu rubripes (TR). Sift scores in bold are predicted to be non-tolerated changes.

comparison studies (see Additional file 3). Seven additional variants in other genes had SIFT scores of less than 0.15 and may have mild functional effects (Table 2).

Of the 22 amino acid alterations that were polymorphic within M. spretus strains, four showed amino acid substitutions that were considered to be intolerant using SIFT (Table 5). These changes all occurred in genes for which there is limited homology data for other species which may lead to over prediction of intolerance by SIFT. Five other substitutions resulted in SIFT scores of 0.15 or lower including 1110049B09Rik Pro691Ala and Lrrn3 Ala69Gln. Polymorphisms in highly conserved amino acids may result in functional differences in these proteins and could account for phenotypic differences between $M$. spretus strains.

\section{Polymorphisms at splice sites}

Variants that fall at highly conserved splice acceptor or splice donor sites may also affect protein function due to 
Table 3: Characteristics of nucleotide substitutions at Skts5

\begin{tabular}{lllllllll}
\hline & 5'UTR & Neutral & AA & 3'UTR & Potential splice sites & SnoRNA & Total & Frequency of substitution/nt \\
\hline C:G to T:A & 27 & 203 & 41 & 140 & 13 & 10 & 434 & 0.00309 \\
\hline T:A to C:G & 30 & 142 & 40 & 123 & 6 & 14 & 355 & 0.00253 \\
\hline C:G to A:T & 7 & 26 & 19 & 52 & 0 & 6 & 110 & 0.00078 \\
\hline T:A to G:C & 9 & 26 & 7 & 29 & 0 & 2 & 73 & 0.00052 \\
\hline C:G to G:C & 8 & 19 & 18 & 25 & 1 & 2 & 73 & 0.00052 \\
\hline T:A to A:T & 9 & 9 & 7 & 35 & 3 & 1 & 64 & 0.00046 \\
\hline total & 90 & 425 & 132 & 404 & 23 & 35 & 1109 & 0.0079 \\
\hline Frequency of substitution/nt & 0.00064 & 0.00303 & 0.00094 & 0.00288 & 0.00016 & 0.00025 & 0.0079
\end{tabular}

$\mathrm{AA}=$ amino acid substitution, $\mathrm{UTR}=$ untranslated region, $\mathrm{nt}=$ nucleotide

alterations in splicing. Twenty-four variants mapped within $3 \mathrm{bp}$ of a splice site. To test whether these variants affected splicing, we isolated tail RNA from NIH/Ola, outbred spretus and Spret/EiJ and performed RT-PCR using primers from flanking exons. Identically sized bands of roughly the same intensity were observed in all of the strains for nineteen of the primer sets tested indicating that these variants are unlikely to affect splicing (data not shown). Five variants were not tested for effects on splice site alterations because the variations mapped to the first or last exon of the gene.

\section{Comparison of sequence divergence within M. Spretus strains}

Because this was, to our knowledge, the most sequence data generated from multiple M. spretus strains, we were

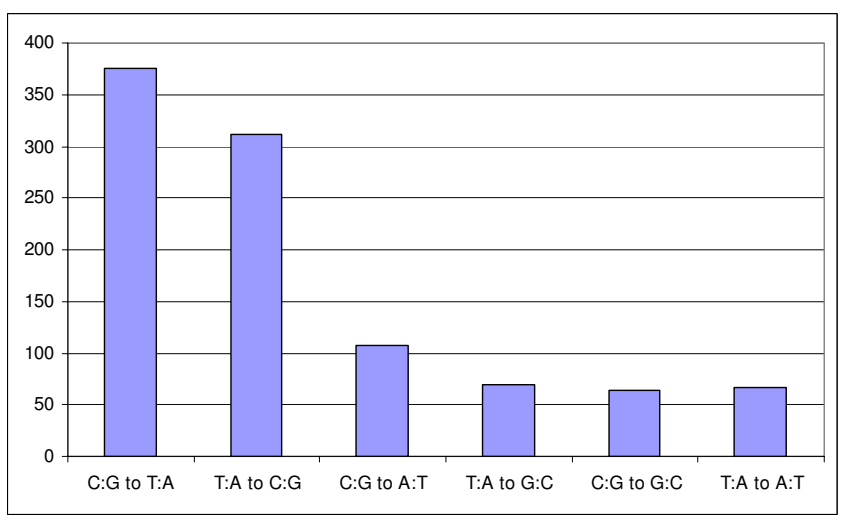

Figure 2

Type and number of nucleotide substitutions. The number of each type of single nucleotide polymorphism identified at Skts5 between NIH/Ola and Spret/Ei] is listed. The transition to transversion rate is roughly 2 -fold. interested in using this information to determine the degree of relatedness between $M$. spretus strains. We therefore conducted maximum parsimony analyses on exon sequence for Spret/EiJ, SEG/PAS, STF/PAS and outbred spretus to FVB/NJ, and NIH/Ola utilizing Phylip 3.66 [30]. We did not include FVB/NT in the analysis as we did not identify any sequence differences between FVB/NT and $\mathrm{NIH} / \mathrm{Ola}$. We included 40,122 bp from coding and flanking exonic regions across Skts 5 on mouse chromosome 12 which represented sequence from 90 exons from 35 genes with the identified amino acid alterations and the noncoding polymorphisms within them. DNA variants were all weighted equally. A maximum parsimony tree was generated from the data which was identical to a consensus tree from 100 bootstrap reiterations (Figure 3). As expected, the greatest phylogenetic distance occurred between the M. musculus and M. spretus groups. The fewest number of polymorphisms occurred between the M. musculus strains $\mathrm{FVB} / \mathrm{NJ}$ and NIH/Ola (FVB/NT) mice. These data suggest that the inbred Swiss-derived strains are more closely related than the wild-derived M. spretus strains. Within M. spretus strains, Spret/EiJ and outbred spretus were the most closely related, and STF/PAS mice showed the most divergence from the other $M$. spretus strains. Nonetheless, of the roughly 13,300 amino acids assessed in all four M. spretus strains only $0.17 \%$ (22 amino acids) were polymorphic between M. spretus strains. If Skts5 is representative of the genome as a whole, then most single nucleotide polymorphism data available for Spret/EiJ from coding regions will have utility for other M. spretus strains.

\section{Discussion and Conclusion}

To our knowledge, this is the largest sequence-based comparison of multiple strains of $M$. spretus. Based on 
Table 4: Candidate variants for Skts5

\begin{tabular}{|c|c|c|c|c|c|}
\hline Gene & Variant & $\mathrm{NIH} / \mathrm{Ola}$ & Outbred spretus & STF/PAS & SIFT \\
\hline $\operatorname{Cog} 5$ & Asp742Glu & Asp & Glu & Asp & 0.92 \\
\hline Hdac9 & Ile265Met & Ile & Met & Ile & 0.33 \\
\hline \multirow[t]{2}{*}{$A h r$} & Asn533Ser & Asn & Ser & Asn & 1.00 \\
\hline & Asn544Asp & Asn & Asp & Asn & 0.66 \\
\hline EG629820 & Asn72Tyr & Asn & Tyr & Asn & 0.00 \\
\hline$Z f p 277$ & Gln2IPhe/Val & Gln & Phe & Val & 0.08 \\
\hline \multirow[t]{2}{*}{ Lrrn3 } & Ala69Gln & Ala & Gln & Ala & 0.08 \\
\hline & Leu670Val & Leu & Val & Leu & 0.23 \\
\hline
\end{tabular}

sequence comparison of over $40 \mathrm{~kb}$ across a $15-\mathrm{Mb}$ region on chromosome $12, M$. spretus strains are more closely related to each other than to the Swiss-inbred strains of $M$. musculus. Outbred spretus and Spret/EiJ have the highest sequence similarity. This is not unexpected as both of these M. spretus mice strains were derived from wild mice isolated from the same region of Spain. STF/PAS mice are derived from mice isolated in Tunisia. This strain showed the highest divergence from the other $M$. spretus strains and was the $M$. spretus strain most closely related to the Swiss-derived M. musculus mice. These data fit with the geographical ascertainment of the lines of $M$. spretus as the other M. spretus strains all come from Spain.

In this dataset we observed an average of one polymorphism every 130 bp between M. musculus and M. spretus. This is less than half as frequent as previous reports of sequence variance between M. musculus and M. spretus [5]. However, this data set was almost entirely restricted to coding regions with only minimal amounts of flanking intronic sequence. Genes are under different mutation constraints than non-functional intragenic regions and therefore show fewer variants [31]. Within the 65 genes analyzed in this study, 31 had no amino acid polymorphisms, 19 genes had one to three amino acid variants and 15 genes had greater than four amino acid variants. Despite the number of non-synonomous changes, the majority of amino acid variants identified in this study were not predicted to show functional consequences using SIFT. Genes and amino acids that showed lower SIFT tolerance scores are being considered as candidates for skin cancer susceptibility.

We conducted this analysis to identify candidate genes for Skts5. From our criteria based on the linkage, a number polymorphisms were identified that were consistent with the linkage (Table 4, Additional file 2). These include eight amino acid changes that were found in outbred spretus that were not seen in STF/PAS including three that have SIFT scores below 0.10 . These variants will be considered as candidates for the linkage. However, the nucleotide driving linkage at Skts5 may also be in a nonsequenced regulatory or intragenic region and may affect gene expression or stability. There is also the small possibility that undetected heterogeneity at Skts5 exists between the outbred spretus mice and we have not sequenced the genome containing the resistance allele. Future studies will address these possibilities.

The five genes that showed the highest number of amino acid polymorphisms (Cog5, Slc26a3, Ahr, Zfp277, $1110049 B 09 R i k)$ do not share any known function and do not map next to each other at Skts5. Ahr (aryl hydrocarbon receptor) mediates the toxicity of dioxin compounds, particularly polycylic aromatic hydrocarbons [32]. It has a large number of reported amino acid variants in both mouse and humans. Some variants within Ahr have been associated with differences in chemical toxicity in mouse and man [33-35] and in modest effects on cancer risk in humans $[36,37]$. One of the amino acids identified in our study shows a very low SIFT score and may therefore affect Ahr function, however this variant was observed in all $M$. spretus strains and is therefore not considered to be a candidate for Skts5. Two Ahr variants, Asn533Ser and Asn544Asp, fit with the linkage data but are not predicted to be functionally significant by SIFT. $\operatorname{Cog} 5$ is part of the conserved oligomeric Golgi ( $\mathrm{cog}$ ) complex and has been postulated to mediate Golgi trafficking. Two amino acid polymorphisms have been reported in human but none in mouse. Little is known about $Z f p 27$. Slc26a3 is a transmembrane glycoprotein that transports sulfate in the lower gut. Slc26a3 has two amino acids reported in 
Table 5: Evolutionary conservation of variants seen between $M$. Spretus strains

\begin{tabular}{|c|c|c|c|c|c|c|c|c|c|}
\hline Gene & Variant & $\mathrm{HS}$ & $\mathrm{RN}$ & GG & BT & $\mathrm{CF}$ & $\mathrm{XT}$ & MD & SIFT \\
\hline LambI-I & Gly|334Asn & Asp & Asp & $\mathrm{NH}$ & $\mathrm{NH}$ & Asp & $\mathrm{NH}$ & $\mathrm{NH}$ & 0.47 \\
\hline \multirow[t]{2}{*}{$\operatorname{Cog} 5$} & Asp538Glu & Asp & Asp & Asp & Asp & Asp & $\mathrm{NH}$ & Glu & 1 \\
\hline & Asp742Glu & Ser & $\mathrm{NH}$ & Asn & Ser & Ser & $\mathrm{NH}$ & Arg & 0.92 \\
\hline II I0049B09rik & Pro69lAla & Pro & Lys & Pro & Pro & Pro & Pro & Pro & 0.11 \\
\hline \multirow[t]{2}{*}{ F730043MI9Rik } & SerlI5Leu & $\mathrm{NH}$ & $\mathrm{NH}$ & $\mathrm{NH}$ & $\mathrm{NH}$ & $\mathrm{NH}$ & $\mathrm{NH}$ & $\mathrm{NH}$ & 0.21 \\
\hline & Asn I33Ile & $\mathrm{NH}$ & $\mathrm{NH}$ & $\mathrm{NH}$ & $\mathrm{NH}$ & $\mathrm{NH}$ & $\mathrm{NH}$ & $\mathrm{NH}$ & 0.00 \\
\hline Twistnb & Asn322Asp & Glu & Asn & Glu & Glu & Glu & Asn & Leu & 0.39 \\
\hline \multirow[t]{3}{*}{ Hdac9 } & Ile265Met & Ile & Ile & Leu & Thr & Ile & Leu & Leu & 0.33 \\
\hline & Gly749Ser & Gly & Gly & Gly & Gly & $\mathrm{NH}$ & $\mathrm{NH}$ & Ala & 1.00 \\
\hline & Ala994Val & Val & Ala & Ile & Val & $\mathrm{NH}$ & $\mathrm{NH}$ & Ile & 1.00 \\
\hline \multirow[t]{2}{*}{ Ahr } & Asn533Ser & Ser & Ser & Ser & Asn & Ser & Asn & Leu & 1.00 \\
\hline & Asn544Asp & Asp & Asp & Asn & Phe & Asp & Asp & Gly & 0.66 \\
\hline \multirow[t]{3}{*}{ EG629820 } & Gly47Ser & $\mathrm{NH}$ & $\mathrm{NH}$ & $\mathrm{NH}$ & $\mathrm{NH}$ & $\mathrm{NH}$ & $\mathrm{NH}$ & $\mathrm{NH}$ & 0.00 \\
\hline & Gly70Ser & $\mathrm{NH}$ & $\mathrm{NH}$ & $\mathrm{NH}$ & $\mathrm{NH}$ & $\mathrm{NH}$ & $\mathrm{NH}$ & $\mathrm{NH}$ & 0.00 \\
\hline & Asn72Tyr & $\mathrm{NH}$ & $\mathrm{NH}$ & $\mathrm{NH}$ & $\mathrm{NH}$ & $\mathrm{NH}$ & $\mathrm{NH}$ & $\mathrm{NH}$ & 0.00 \\
\hline \multirow[t]{2}{*}{$Z f p 277$} & Gln2IPhe & Gln & $\mathrm{NH}$ & Gln & Gln & Gln & Gln & $\mathrm{NH}$ & 0.15 \\
\hline & Val434His & Ser & $\mathrm{NH}$ & $\mathrm{NH}$ & Asn & Arg & $\mathrm{NH}$ & Asp & 0.08 \\
\hline \multirow[t]{3}{*}{ Lrrn3 } & Ala69Gln & Ala & Ala & Ala & Ala & Ala & $\mathrm{NH}$ & Gln & 0.08 \\
\hline & Leu670Val & Phe & Leu & Ile & Phe & Phe & $\mathrm{NH}$ & Ile & 0.23 \\
\hline & Ala67IVal & Ala & Ala & Ser & Ala & Thr & $\mathrm{NH}$ & Phe & 0.15 \\
\hline DnajB9 & PhelOLeu & Phe & Phe & Phe & Phe & Phe & Phe & Ala & 1.00 \\
\hline $\mathrm{NrCam}$ & Gln I52Arg & Gln & Arg & Arg & Arg & $\operatorname{Arg}$ & Gln & Phe & 0.49 \\
\hline
\end{tabular}

Bold indicates significant SIFT scores. No known homology (NH), No sift score generated (NSS) M. musculus (MM) Homo sapiens (HS), Rattus norvegicus (RN), Gallus gallus (GG), Bos Taurus (BT), Canis familiaris (CF), Xenopus tropicalis (XP), and Monodelphis domestica (MD).

human and none in mouse. The function of $1110049 B 09 R i k$ is not known, but the purported human homologue, FLJ23834, has a large number of reported amino acid alterations as well (seven in mouse; six in humans). It is possible that the higher rate of amino acid substitution in these genes reflects some underlying selection pressures between M. musculus and M. spretus.
A number of potentially functional interesting variants were identified that do not fit with the linkage data. The only species in which the Sostdc1 amino acid variant Cys15Ser was observed was in M. spretus. It is not known if substitution of a cysteine at position 15 with serine in the M. spretus isoform results in altered disulfide bond formation, disruption of other secondary structure or other 


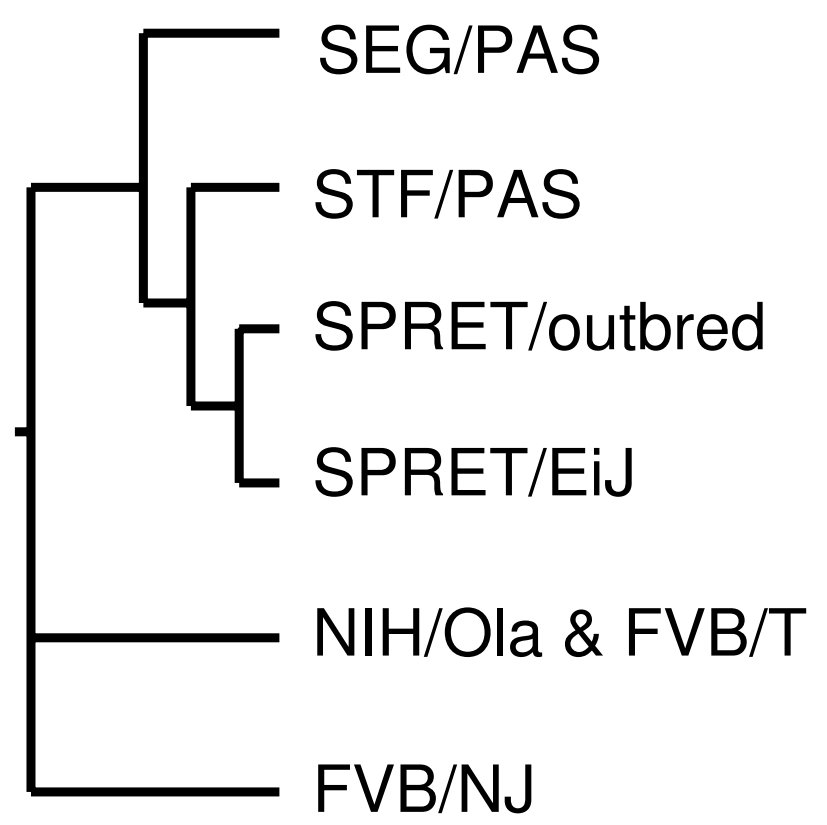

Figure 3

Phylogenetic tree from sequence data at Skts5. Phylogenetic tree generated by parsimony analysis of four M. Spretus and two Swiss-derived M. musculus strains. DNAPars program from Phylip 3.66 was used to generate a parsimony tree from $40.1 \mathrm{~kb}$ of sequence data from mouse chromosome 12 derived from six of the seven mouse strains.

Because no sequence differences existed between FVB/NT and $\mathrm{NIH} / \mathrm{Ola}$ these mice were grouped on the tree. The four $M$. spretus strains cluster together. The STF/PAS mice show the greatest divergence within M. spretus.

functional consequence. Another interesting polymorphism is in 4921508 M14Rik. This gene contains a stop codon at position 109 in all of the $M$. spretus strains theoretically resulting in a truncated protein missing the 37 terminal amino acids. The function of this gene is unknown. EG629820, which contains several amino acid variants thought to be functional by SIFT, is a predicted gene that has shown expression differences of unknown biological consequence in a number of murine studies [38].

There was a relatively low degree of sequence variation between the $M$. spretus strains; however we identified twenty-two changes that resulted in intra-spretus amino acid polymorphisms. Thus, based on this dataset, nearly twenty percent of the amino acid alterations identified between $M$. spretus and $M$. musculus are polymorphic within $M$. spretus. In contrast, sequencing results from the two Swiss-derived M. musculus strains identified only one amino acid that was polymorphic between the FVB/NJ strain and NIH/Ola. Sequence comparison of three closely related $M$. musculus strains: NIH/Ola, FVB/NT and FVB/NJ revealed only six of 140,448 basepairs $(0.004 \%)$ that were polymorphic between NIH/Ola and FVB/NJ. There were no sequence differences identified between FVB/NT and NIH/Ola. Because sequence variants exist between $\mathrm{FVB} / \mathrm{NT}$ and $\mathrm{FVB} / \mathrm{NJ}$, researchers comparing results across studies should be aware of which strain of FVB/N is used. Our results confirm previous studies in which variations in coding regions were more common in wild-mice than in laboratory-derived strains [7], perhaps reflecting differences in breeding and selection pressure.

Our data comparing sequence diversity between $M$. spretus strains may not be representative of genome as a whole since this study was limited to one locus on chromosome 12 and included only genes, predicted coding elements, and small amounts of flanking intronic sequences. In this study, we conducted our sequence comparisons by analyzing only exons in which we initially identified an amino acid variation between outbred spretus, Spret/EiJ, FVB/N, and NIH/Ola. There may be additional amino acid variations at Skts5 in which Spret/EiJ, outbred spretus and NIH/Ola share an allele that is different from the other strains of $M$. spretus. We also cannot rule out the possibility that Skts5 may have unique genomic properties compared to other loci. Previous studies have reported different phylogenetic trees when comparing sequence samples from across the genome (global comparison) with gene-specific phylogenetic trees (local comparison)[39]. Skts5 may represent a region with unique local characteristics between $M$. spretus strains. For instance, Skts5 may be under differential evolutionary constraints against sequence divergence in $M$. spretus strains. Nonetheless, our data suggest that genomic data and single nucleotide markers in the database for Spret/EiJ, particularly intragenic SNPs, are more likely to be shared with other M. spretus strains than with M. musculus strains, increasing the utility of the publicly available SNP maps for studies utilizing any $M$. spretus mouse.

\section{Methods \\ Animal material}

The ancestral and laboratory origins of each of the mice in the study are as follows: SEG/PAS (Grenada, Spain, inbred line maintained by the Institute Pasteur), STF/PAS (Fondouk el Djedid, Tunisia, inbred line maintained by the Institute Pasteur), Spret/EiJ (Puerto Real, Ibiza, Spain, inbred line maintained by the Jackson Laboratories), outbred spretus (Spain, outbred line maintained by Stephen Brown, PhD of the Medical Research Council, Harwell, England), FVB/NT (Switzerland, inbred line maintained by Taconics, US), FVB/NJ (Switzerland, inbred line maintained by the Jackson laboratories) and NIH/Ola (Switzerland, inbred line maintained by Harlan Olac, UK). DNA was isolated from tails or spleens of outbred spretus, NIH/ 
Ola and FVB/NT mice using standard methods [40]. Spret/EiJ and FVB/NJ DNA was purchased from the Jackson Laboratories. STF/PAS and SEG/PAS DNAs were a gift from Xavier Montagutelli, DVM, PhD of the Institut Pasteur.

\section{Linkage analysis and genotyping of markers at Skts5} To refine linkage at $S k t s 5$ in the outbred spretus $\times$ NIH/Ola backcross ten additional single nucleotide polymorphisms from chromosome 12 were genotyped in mice at Applied Biosystems. Genotypes of the new markers were combined with previously genotyped microsatellite markers D12Mit182, D12Mit242, D12Mit60, D12Mit153, D12Mit154, D12Mit2, D12Mit68, and D12Mit5. Quantitative trait locus analysis using WinQTLCart [41] was conducted on the genotypes of the 18 markers on 351 intercross mice using skin papilloma number as the trait. To rule out genetic heterogeneity within outbred spretus mice at Skts5 (15-19 cM), we genotyped seven additional markers (D12Mit243, D12Mit187, D12Mit146, D12Mit186, D12Mit222, D12Mit61 and D12Mit62) in six different outbred spretus fathers, Spret/EiJ, NIH/Ola, and NIH/Ola $\times$ outbred spretus F1 and STF/PAS.

\section{PCR primer design, sequencing and analysis}

Intron/exon boundaries of all genes and coding regions mapping to Skts5 were identified using the Ensembl database, builds 35-48. When multiple splice forms of a gene were present, exons from all splice forms were included in the analyses. We designed PCR primers using Integrated DNA Technology's SciTools PrimerQuest web-based program [42]. Primer sequences and PCR conditions are listed in Additional file 4. PCR products were treated with Exo/SAP-IT to remove single stranded DNA (USB). Automated sequencing of PCR products was conducted on an ABI 3700 by standard methods. Primers used for PCR were also used for the sequencing. Forward and reverse sequences were analyzed and compared using DNAstar 3.0. The sequence traces were inspected visually whenever a nucleotide substitution was indicated. When a polymorphism was identified between FVB/NJ and Spret/EiJ, PCR products from additional strains NIH/Ola, FVB/NT, outbred spretus, SEG/PAS and STF/PAS were sequenced.

\section{Evolutionary comparison}

Sequence alignments between M. musculus and other species were obtained from the Ensembl database when homologies were present. Tolerance scores were generated using the SIFT program and entering in the NCBI protein G numbers for each M. musculus gene at Skts5 [29]. SIFT sorts intolerant amino acid substitutions from tolerant substitutions by protein based alignments from other species. A tolerance score of 0 to 1.0 is generated for each amino acid variant. Low tolerance indices (less than 0.05) are suggested of non-tolerated (deleterious or functional) amino acid substitutions. Higher tolerance indices indicate that an amino acid substitution is less likely to have functional consequences.

\section{Splicing Studies}

RNA was isolated from tails of NIH/Ola, Spret/EiJ and outbred spretus mice using standard Trizol methods per manufacturer's recommendations (Invitrogen). One microgram of RNA was reversed transcribed using the Iscript cDNA synthesis kit (Biorad) according to manufacturer's directions. PCR primers were designed in exons flanking the potentially aberrantly spliced exon. Primer sequences and PCR conditions are listed in Additional file 4. Genomic DNA from the mice was used as a negative control. PCR products were run on $1.5 \%$ agarose gels for comparison of product sizes.

\section{Phylogenetic comparison}

Maximum DNA parsimony analyses were conducted using sequence from exons that were sequenced in all strains of mice using the DNAPars program included in the Phylogeny Interference Package (Phylip) version 3.66 [30]. All nucleotide changes were weighted equally. To assess support for the most parsimonious tree, we also performed a bootstrap analysis and compared the resulting consensus tree to the most parsimonious tree. This resulted in an identical tree. We used the program Drawgram in Phylip 3.66 to construct a phylogenetic tree from this data without using branch length considerations.

\section{Abbreviations}

Phylip: Phylogeny Interference Package; QTL: Quantitative trait loci; Skts5: Skin tumor susceptibility 5; SIFT: Sorting tolerant from intolerant.

\section{Authors' contributions}

KLM participated in sequence analysis, phylogenetic analysis and organization and interpretation of data. JLF, HYC, NG and AMD contributed to sequence analysis and organization of data. $\mathrm{AB}$ and JHM contributed to linkage data. AET conceived the study, participated in data analysis and coordination and helped to draft the manuscript. All authors participating in editing of the final manuscript. All authors read and approved the final manuscript.

\section{Additional material}

\section{Additional file 1}

Table 1: Genes mapping to Skts5. This table shows a list of all genes mapping to Skts5 including their Ensembl reference number.

Click here for file

[http://www.biomedcentral.com/content/supplementary/14712164-9-626-S1.xls] 


\section{Additional file 2}

Table 2: All sequence variants identified at Skts5. This table shows all the sequence variants identified in the study, the strain of mouse in which it was found, the amino acid change if applicable, and the rs number if previously entered in $d b S N P$.

Click here for file

[http://www.biomedcentral.com/content/supplementary/14712164-9-626-S2.xls]

\section{Additional file 3}

Table 3: Genes showing strong conservation across species. This table shows a list of amino acid changes that appear to be strongly conserved across species. In red are the amino acids that match M. musculus and in blue are the amino acids that match $M$. Spretus. The corresponding amino acids in nine species as well as the mouse strains sequenced in the study are shown.

Click here for file

[http://www.biomedcentral.com/content/supplementary/14712164-9-626-S3.xls

\section{Additional file 4}

Table 4: Primers for each exon for sequencing and splice site analysis. This table lists all forward and reverse primers used for sequencing in this study.

Click here for file

[http://www.biomedcentral.com/content/supplementary/14712164-9-626-S4.xls]

\section{Acknowledgements}

We thank Dr. Laura Kubatko for her thoughtful advice on phylogenetic analyses. We thank the Ohio State University Comprehensive Cancer Center Nucleic Acids Shared Resource for sequencing support (supported by a $\mathrm{NIH} / \mathrm{NCl}$ cancer center support grant). This work was supported in part by the Concern Foundation and the American Cancer Society RSG-07083-0I-MGO (AET).

\section{References}

I. Bonhomme F, Guenet JL: The laboratory mouse and its wild relatives. In Genetic variants and strains of the laboratory mouse Volume 2. 3rd edition. Edited by: Lyon MF, Rastan S, Brown SDM. Oxford, England: Oxford University Press; 1996:1577-1596.

2. Hochepied T, Schoonjans L, Staelens J, Kreemers V, Danloy S, Puimege L, Collen D, Van Roy F, Libert C: Breaking the species barrier: derivation of germline-competent embryonic stem sells from Mus spretus $\times$ C57BL/6 Hybrids. Stem Cells 2004, 22(4):44|-447.

3. She JX, Bonhomme F, Boursot P, Thaler L, Catzeflis FM: Molecular phylogenics in the genus Mus: comparative analysis of electrophoretic scnDNA hybridization and mtDNA RFLP data. Biol J Linn Soc 1990, 4I(1):83-103.

4. Suzuki H, Shimada T, Terashima M, Tsuchiya K, Aplin K: Temporal, spatial, and ecological modes of evolution of Eurasian Mus based on mitochondrial and nuclear gene sequences. Mol Phylogenet Evol 2004, 33(3):626-646.

5. Zhang J, Wheeler DA, Yakub I, Wei S, Sood R, Rowe W, Liu PP, Gibbs RA, Buetow KH: SNPdetector: A Software Tool for Sensitive and Accurate SNP Detection. PLoS Comput Biol 2005, I(5):e53.

6. de Gouyon B, Melanitou E, Richard MF, Requarth M, Hahn IH, Guenet JL, Demenais F, Julier C, Lathrop GM, Boitard C, et al.: Genetic analysis of diabetes and insulitis in an interspecific cross of the nonobese diabetic mouse with Mus spretus. Proc Natl Acad Sci USA 1993, 90(5):|877-|88|.
7. Guenet JL, Bonhomme F: Wild mice: an ever-increasing contribution to a population mammalian model. Trends Genet 2003, 19(1):24-31.

8. Staelens J, Wielockx B, Puimege L, Van Roy F, Guenet JL, Libert C Hyporesponsiveness of SPRET/Ei mice to lethal shock induced by tumor necrosis factor and implications for a TNF-based antitumor therapy. Proc Natl Acad Sci USA 2002, 99(14):9340-9345.

9. Staelens J, Puimege L, Mahieu T, Pynaert G, Hochepied T, Vandenabeele A, Grooten J, Kontoyiannis D, Van Roy F, Kollias G, et al.: Response of TNF-hyporesponsive SPRET/Ei mice in models of inflammatory disorders. Mamm Genome 2004, I 5(7):537-543.

10. Stephan K, Smirnova I, Jacque B, Poltorak A: Genetic analysis of the innate immune responses in wild-derived inbred strains of mice. Eur J Immunol 2007, 37(I):2 I2-223.

II. Nagase H, Bryson S, Cordell H, Kemp CJ, Fee F, Balmain A: Distinct genetic loci control development of benign and malignant skin tumors in mice. Nat Genet 1995, 10(4):424-429.

12. Nagase $\mathrm{H}$, Mao JH, Balmain $\mathrm{A}$ : $\mathbf{A}$ subset of skin tumor modifier loci determines survival time of tumor-bearing mice. Proc Natl Acad Sci USA 1999, 96(26): $15032-15037$.

13. Ewart-Toland A, Briassouli P, de Koning JP, Mao JH, Yuan J, Chan F, MacCarthy-Morrogh L, Ponder BA, Nagase H, Burn J, et al.: Identification of Stk6/STK I 5 as a candidate modifier of cancer risk in mouse and man. Nat Genet 2003, 34(4):403-4I2.

14. Benelli R, Peissel B, Manenti G, Gariboldi M, Vanzetto C, Albini A, Dragani TA: Allele-specific patterns of the mouse parathyroid hormone-related protein: influences on cell adhesion and migration. Oncogene 2003, 22(49):77|I-77। 5 .

15. Santos J, Montagutelli X, Acevedo A, Lopez P, Vaquero C, Fernandez M, Szatanik M, Salido E, Guenet JL, Fernandez-Piqueras J: A new locus for resistance to gamma-radiation-induced thymic lymphoma identified using inter-specific consomic and interspecific recombinant congenic strains of mice. Oncogene 2005, $21(43): 6680-6683$

16. To MD, Perez-Losada J, Mao JH, Hsu J, Jacks T, Balmain A: A functional switch from lung cancer resistance to susceptibility at the PasI locus in Kras2LA2 mice. Nat Genet 2006, 38(8):926-930.

17. Greene-Till R, Zhao Y, Hardies SC: Gene flow of unique sequences between Mus musculus domesticus and Mus Spretus. Mamm Genome 2000, I I(3):225-230.

18. Prager EM, Tichy H, Sage RD: Mitochondrial DNA sequence variation in the eastern house mouse, Mus Musculus: comparison with other house mice and report of a 75-bp tandem repeat. Genetics 1996, I43(1):427-446

19. Villa-Morales M, Santos J, Fernandez-Piqueras J: Functional fas (cd95/apo-I) promoter polymorphisms in inbred mouse strains exhibiting different susceptibility to gamma-radiation induced thymic lymphoma. Oncogene 2006, 25( I 4):2022-2029.

20. Nagase $\mathrm{H}$, Mao JH, de Koning JP, Minami T, Balmain A: Epistatic interactions between skin tumor modifier loci in interspecific (Spretus/musculus) backcross mice. Cancer Res 200I, 6I(4): I305-1308.

21. Mao JH, Saunier EF, de Koning JP, McKinnon MM, Higgins MN, Nicklas $\mathrm{K}$, Yang HT, Balmain A, Akhurst RJ: Genetic variants of Tgfb I act as context-dependent modifiers of mouse skin tumor susceptibility. Proc Natl Acad Sci USA 2006, I03(2 I):8I25-8I30.

22. Chasman $D$, Adams RM: Predicting the functional consequences of non-synonymous single nucleotide polymorphisms: structure-based assessment of amino acid variation. J Mol Bio 200I, 307(2):683-706.

23. Chamary JV, Parmley JL, Hurst LD: Hearing silence: non-neutral evolution at synonymous sites in mammals. Nat Rev Genet 2006, 7(2):98-108.

24. Sunyaev S, Ramensky V, Koch I, Lathe W, Kondrashov AS, Bork P: Prediction of deleterious human alleles. Hum Mol Genet 200I, I0(6):59I-597.

25. Sjoblom T, Jones S, Wood LD, Parson DW, Lin J, Barber TD, Mandelker D, Leary RJ, Ptak J, Silliman N, et al.: The consensus coding sequences of human breast and colorectal cancers. Science 2006, 3 I 4(5797):268-274.

26. Zhang Z, Gerstein M: Patterns of nucleotide substitution, insertion and deletion in the human genome inferred from pseudogenes. Nucl Acids Res 2003, 3 I (18):5338-5348. 
27. Savas S, Taylor IW, Wrana JL, Ozcelik H: Functional non-synonymous single nucleotide polymorphisms from the TGF-\{beta\} protein interaction network. Phyisiol Genomics 2007, 29(2):109-117.

28. Zhu Y, Spitz MR, Amos Cl, Lin J, Schabath MB, Wu X: An Evolutionary Perspective on Single-Nucleotide Polymorphism Screening in Molecular Cancer Epidemiology. Cancer Res 2004, 64(6):225I-2257.

29. Ng PC, Henikoff SS: Accounting for human polymorphisms predicted to affect protein function. Genome Res 2002, I 2(13):436-46.

30. PHYLLIP [http://evolution.genetics.washington.edu/phylip.html]

31. Liu GE, Matukumalli LK, Sonstegard TS, Shade LL, Van Tassel CP: Genomic divergences among cattle, dog and human estimated from large-scale alignments of genomic sequences. BMC Genomics 2006, 7: | 40-153.

32. Shimuzu $Y$, Nakatsuru $Y$, Ichinose $M$, Takahashi $Y$, Kume $H$, Mimura J, Fujii-Kuriyama $Y$, Ishikawa $\mathrm{T}$ : Benzo[a]pyrene carcinogenicity is lost in mice lacking the aryl hydrocarbon receptor. Proc Natl Acad Sci USA 2000, 97(2):779-782.

33. Connor KT, Aylward LL: Human response to dioxin: aryl hydrocarbon receptor (AhR) molecular structure, function, and dose-response data for enzyme induction indicate an impaired human AhR. J Toxicol Environ Health B Crit Rev 2006, 9(2): $|47-| 7 \mid$.

34. Okey AB, Franc MA, Moffat ID, Tijet N, Boutros PC, Korkalainen M, Tuomisto J, Pohjanvirta R: Toxicological implications of polymorphisms in receptors for xenobiotic chemicals: The case of the aryl hydrocarbon receptor. Toxicol Appl Pharmacol 2005, 207(2 Suppl):43-5I.

35. Abnet CC, Fagundes RB, Strickland PT, Kamangar F, Roth MJ, Taylor $P R$, Dawsey SM: The influence of genetic polymorphisms in Ahr, CYPIAI, CYPIA2, CYPIBI, GST MI, GST TI and UGTIAI on urine I-hydroxypyrene glucuronide concentrations in healthy subjects from Rio Grande do Sul, Brazil. Carcinogenesis 2007, 28(I): I I2-II7.

36. Kim JH, Kim H, Lee KY, Kang JW, Lee KH, Park SY, Yoon HI, Jheon SH, Sung SW, Hong YC: Aryl hydrocarbon receptor gene polymorphisms affect lung cancer risk. Lung Cancer 2007, 56(I):9-15.

37. Long JR, Egan KM, Dunning L, Shu XO, Cai Q, Cai H, Dai Q, Holtzman J, Gao YT, Zheng W: Population-based case-control study of AhR (aryl hydrocarbon receptor) and CYPIA2 polymorphisms and breast cancer risk. Pharmacogenet Genomics 2006, 16(4):237-243.

38. Katayama S, Tomaru Y, Kasukawa T, Waki K, Nakanishi M, Nakamura M, Nishida H, Yap CC, Suzuki M, Kawai J, Suzuki H, Carninci P, Hayashizaki Y, Wells C, Frith M, Ravasi T, Pang KC, Hallinan J, Mattick J, Hume DA, Lipovich L, Batalov S, Engström PG, Mizuno Y, Faghihi MA, Sandelin A, Chalk AM, Mottagui-Tabar S, Liang Z, Lenhard B, Wahlestedt C, RIKEN Genome Exploration Research Group; Genome Science Group (Genome Network Project Core Group); FANTOM Consortium: Antisense transcription in the mammalian transcriptome. Science 2005, 309(5740): I564-I566.

39. Park YG, Lukes L, Yang H, Debies MT, Samant RS, Welch DR, Lee M, Hunter KW: Comparative sequence analysis in eight inbred strains of the metastasis modifier QTL candidate gene Brms I. Mamm Genome 2002, I3(6):289-292.

40. Laird PW, Zijderveld A, Linders K, Rudnicki MA, Jaenisch R, Burns A Simplified mammalian DNA isolation procedure. Nucl Acids Res 1991, 19(15):4293.

4I. Wang S, Basten CJ, Zeng ZB: Windows QTL Cartographer 2.5. 2007 [http://statgen.ncsu.edu/qtlcart/WQTLCart.htm]. Department of Statistics, North Carolina State University, Raleigh, NC

42. IDT SciTools Primer Quest [http://www.idtdna.com/Scitools/ Applications/Primerquest]

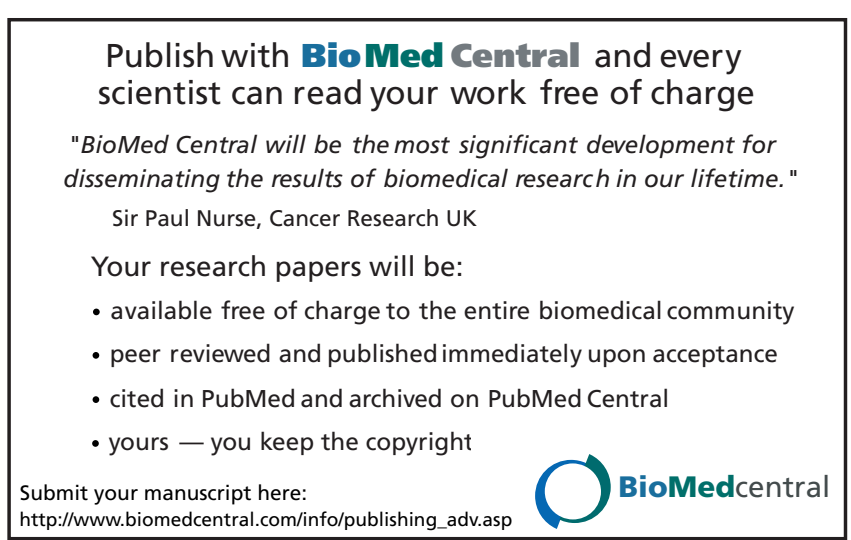

